\title{
Puberty and Athletic Sports in Female Adolescents
}

\author{
Panagiota (Nota) Klentrou \\ Department of Physical Education and Kinesiology, Brock University, St. Catharines, Canada
}

\begin{abstract}
Key Words
Female athletes, training/growth/maturation $\cdot$ Hormonal development $\cdot$ Menarche $\cdot$ Reproductive function $\cdot$ Body composition - Dietary restriction $\cdot$ Amenorrhea, athletic
\end{abstract}

\begin{abstract}
The increasing involvement of young children in intense physical training over the past several decades has generated concerns as to its potential effects on children's growth and maturation. Puberty in humans is characterized by large hormonal changes resulting in both physical and sexual maturation. Since intense training prior to puberty, together with the potential metabolic effects of dieting, can alter hypothalamic-pituitary function, the time at which athletic training is initiated has been implicated as a factor in delayed menarche and sexual maturation in female athletes. On the other hand, some studies have suggested that delayed menarche is likely due to genetic factors. Girls who mature later often self-select or are recruited by coaches into sports that favor small or very lean bodies. Body composition has also been used to explain both delayed menarche and menstrual irregularities observed among elite athletes. A higher prevalence of menstrual dysfunction has been reported for adolescent athletes participating in weight-dependent sports as compared to that observed in other sports. However, as recently suggested, there is no direct cause-effect association
\end{abstract}

between fatness and reproduction and, in actual fact, energy availability, and not body fat, regulates reproductive function in females. More research is warranted to further investigate this interaction between short-term changes in fuel availability and athletic amenorrhea in female adolescents. It is concluded that, given the many factors that have been shown to influence menarche and menstruation, the role played by physical training alone as a causative factor in the later onset of puberty and menstrual irregularities in active young females is still unclear. Research involving longitudinally designed studies is required to identify whether the maturity differences observed between female athletes and non-athletes are the result of nature or nurture, and what the balance between the two factors is.

Copyright $\odot 2006$ Nestec Ltd., Vevey/S. Karger AG, Basel

\section{Introduction}

Puberty is a significant event in human growth and maturation, one that is associated with marked physiological and psychological changes, and one that is characterized by significant neuroendocrine adjustments. Thus, during her pubertal years, the hormonal milieu of an adolescent athlete goes through a series of developmentally induced, ever-changing, and training-derived adaptations.

\section{KARGER \\ Fax +41613061234 \\ E-Mail karger@karger.ch}

www.karger.com
(C) 2006 Nestec Ltd., Vevey/S. Karger AG, Basel

0517-8606/06/0642-0085\$23.50/0

Accessible online at:

www.karger.com/ane
Nota Klentrou, PhD

Department of Physical Education and Kinesiology

Brock University

St. Catharines, Ont. L6L 3M7 (Canada)

Tel. +1 905 688 5550/ext. 4538, Fax +1 905688 8364, E-Mail nota.klentrou@brocku.ca 
The growing number of female adolescents competing in sporting events during the past few decades has led to an increased interest in the physiology of the exercising young female. Growth and maturation are characterized by individual variation, and although under genetic and neuroendocrine control, environmental factors, including the type, intensity and duration of training, can also have an influence [1]. To date, our understanding of the effect that sports training has on the growing child, especially females, is limited because of the difficulty in distinguishing the effects of training from those of normal growth [1]. Therefore, the effect of intense training on the growth and maturation of young girls participating in competitive sports creates parallel physiological actions which are interactive and sometimes opposing, with potential implications for the health and development of the exercising female adolescent. Of course, nutrition is also an important consideration due to its role in both physical maturation and proper metabolic functioning during training and performance.

This article will examine the response to intense training prior to and during puberty in young females. It will be shown that in elite female athletes, especially younger ones, the combination of intense training and inadequate nutrition often results in delayed menarche and menstrual irregularities that can lead to health complications later in life. The discussion will further focus on whether the maturity differences observed between young female athletes and non-athletes are the result of nature, nurture, or a combination of both.

\section{Puberty and Menstruation}

The normal process of the female menstrual cycle is regulated by a series of complex interactions of pituitary and ovarian hormones. These hormones include the gonadotropin-releasing hormone $(\mathrm{GnRH})$ secreted by the hypothalamus and target the pituitary to release folliclestimulating hormone (FSH) and luteinizing hormone (LH). During childhood, the hypothalamus is sensitive to low levels of estrogen, which exert a negative feedback effect inhibiting hypothalamic activity. The exact trigger for puberty and menarche is still not well understood; the appearance of related events, as well as the timing of menarche, varies greatly and is influenced by nutrition, heredity, state of health, percentage of body fat, growth hormone and other growth factors, and maturation of the hypothalamic-pituitary axis, which is itself dependent on multiple factors [2-4]. In general, puberty is initiated in females when the hypothalamus matures and becomes less sensitive to negative feedback, promoting an increase in the secretion of GnRH by the neurosecretory cells within the hypothalamus, which in turn triggers the anterior pituitary to begin the secretion of the gonadotropic hormones, LH and FSH. Sufficient quantities of FSH and LH stimulate ovarian follicular development, the development of secondary sex characteristics, and an increased release of female sex steroids (estrogen and progesterone) from the ovaries [2]. Estrogen and progesterone continue to increase throughout puberty, and play a key role in both physical and sexual maturation [3]. Throughout the phases of the menstrual cycle, FSH promotes the development of the follicle and the secretion of estrogen by the ovaries, while LH stimulates ovulation and the secretion of estrogen and progesterone. The menstrual cycle begins with menstruation. In the follicular phase, the days prior to ovulation, the levels of FSH and LH increase, with estrogen being predominant. After ovulation occurs, during the luteal phase of the cycle, progesterone exceeds estrogen as the uterus is prepared for a potential pregnancy.

Female athletes are often concerned regarding the number of days of menstruation and the volume of menstrual flow. A normal cycle is often described as being on the average 28 days in length, but in reality, a 28 -day cycle occurs in only $12.4 \%$ of all cycles. Studies on the length of regular menses have shown variations in the length of 'normal' as ranging from 21 to 35 days [2, 3]. Menstrual duration also varies considerably, with normal flow lasting for an average of 2-8 days $[2,3]$.

It has been suggested that estrogen (primarily the estradiol component) and progesterone can be altered by intense exercise. Studies have shown that physiological changes occur in both the follicular and luteal phase with both aerobic or anaerobic training and performance [5].

\section{Onset of Puberty in Female Athletes}

The increasing involvement of young children in intense physical training over the past decades has generated concerns as to the potential effects on children's growth, maturation, and reproductive function [6]. Intense training has been found to delay the onset of puberty in females by altering normal hormonal development $[7,8]$. Delayed pubertal growth spurt, delayed age at first menarche, and delayed skeletal maturation have been reported in young girls involved in athletic training for at least $15 \mathrm{~h} /$ week [9]. Most discussions on the potential influence of physical training on sexual maturation 
Table 1. Age at menarche (mean \pm SD) of adolescent athletes and non-athletes

\begin{tabular}{|c|c|c|c|}
\hline Study & Country & Sport group & $\begin{array}{l}\text { Age at menarche } \\
\text { years }\end{array}$ \\
\hline Torstveit and Sundgot-Borgen [10], 2005 & Norway & $\begin{array}{l}\text { Elite female athletes }(n=669) \\
\text { Age-matched controls }(n=607)\end{array}$ & $\begin{array}{l}13.4 \pm 1.4^{*} \\
13.0 \pm 1.3\end{array}$ \\
\hline Klentrou and Plyley [11], 2003 & Canada & $\begin{array}{l}\text { Rhythmic gymnasts }(\mathrm{n}=30) \\
\text { Age-matched controls }(\mathrm{n}=40)\end{array}$ & $\begin{array}{l}13.6 \pm 1.2^{*} \\
12.3 \pm 0.8\end{array}$ \\
\hline Dusek [12], 2001 & Croatia & $\begin{array}{l}\text { Athletes trained before menarche }(\mathrm{n}=34) \\
\text { Athletes trained after menarche }(\mathrm{n}=33) \\
\text { Age-matched controls }(\mathrm{n}=96)\end{array}$ & $\begin{array}{l}13.8 \pm 1.4^{*} \\
12.6 \pm 1.0 \\
13.0 \pm 1.2\end{array}$ \\
\hline Pigeon et al. [13], 1997 & France & $\begin{array}{l}\text { Ballet dancers }(\mathrm{n}=97) \\
\text { Controls }(\mathrm{n}=30)\end{array}$ & $\begin{array}{l}13.5^{*} \\
12.0\end{array}$ \\
\hline Lindholm et al. [4], 1994 & Sweden & $\begin{array}{l}\text { Artistic gymnasts }(\mathrm{n}=22) \\
\text { Controls }(\mathrm{n}=22)\end{array}$ & $\begin{array}{l}14.5 \pm 1.4^{*} \\
13.2 \pm 0.9\end{array}$ \\
\hline Malina et al. [15], 1994 & USA & 7 sports - mixture of athletes $(n=109)$ & $13.8 \pm 1.5$ \\
\hline Hata and Aoki [16], 1990 & Japan & $\begin{array}{l}\text { Elite athletes }(n=40) \\
\text { College athletes }(n=386) \\
\text { High school athletes }(n=253)\end{array}$ & $\begin{array}{l}13.5 \pm 1.3 \\
12.9 \pm 1.2 \\
12.6 \pm 1.1\end{array}$ \\
\hline Calabrese [17], 1985 & USA & Artistic gymnasts $(\mathrm{n}=20)$ & 14.2 \\
\hline Calabrese et al. [18], 1983 & USA & Ballet dancers $(n=25)$ & 14.3 \\
\hline
\end{tabular}

${ }^{*} \mathrm{p} \leq 0.05$ (reported difference between athletes and controls).

have focused on the increase in mean age at first menarche that is often reported in adolescent female athletes $[4,10$ 19]. Table 1 summarizes international data on the age at menarche in young female athletes as compared to nonathletic controls. However, some studies have suggested that delayed menarche is due to genetic factors, and those girls who mature later often self-select sports which require high relative muscle strength and small bodies, such as gymnastics [20]. According to Kaprio et al. [21], 37\% of the variance in the age at menarche was found to be attributed to additive genetic factors. In addition, the correlation between the additive genetic effects on age at menarche and body mass index (weight/height ${ }^{2}$ ) was 0.57 , indicating a substantial proportion of genetic effects. The limited longitudinal data for girls participating in sports compared with non-athletic girls indicated no effect of training on either the timing or the progress of secondary sexual characteristics, including breast and pubic hair development [22].

Since intense training prior to puberty may alter hypothalamic-pituitary function, the time at which athletic training is initiated has been implicated as a factor in delayed menarche. Female athletes who begin training at a young age often have a delay in menarche [23]. According to Dusek [12], menarche has been reported to be significantly delayed in Croatian athletes who started physical activities before the onset of menstruation (13.8 $\pm 1.4 \mathrm{vs}$. $12.6 \pm 1.0$ years; $\mathrm{p} \leq 0.001$ ). Body composition has also been used to explain delayed menstruation and menstrual cycle irregularities among elite athletes. Although not supported by current opinion, Frisch and McArthur [24] have theorized an association between menstrual regular- 
ity and the level of body fat, suggesting that a level of at least $17 \%$ body fat is critical for the onset of menstruation and the maintenance of a normal cycle. Recent epidemiological data have shown that age at menarche was significantly $(\mathrm{p}<0.001)$ later in athletes than in controls $(13.4$ \pm 1.4 vs. $13.0 \pm 1.3$ years, respectively), and differed among sport groups, with athletes participating in 'leanness' sports reporting the greatest delay [10]. Therefore, activities of concern include aesthetic and leanness activities such as gymnastics, figure skating, dance, as well as sports where weight control is an integrated performance strategy, and any sport in which initiation of intense physical training begins at a very young age.

Reports in the literature describe the weekly training volumes of young prepubertal and/or early pubertal artistic gymnasts to be as long as $36 \mathrm{~h} /$ week [25]. It is not surprising, therefore, that some authors have described elite female gymnasts as being at risk of delayed maturation $[23,26,27]$. Growth potential has been found to be reduced and menarche has been reported to be delayed in artistic gymnasts $[4,8,26]$. However, there is considerable controversy as to whether the growth potential of elite artistic gymnasts is affected by the intense training, which is often initiated before puberty. Longitudinal data for female gymnasts that span late childhood and adolescence are limited. Results of two short-term longitudinal studies have suggested that gymnasts advance through puberty with a less intense pubertal growth spurt [26, 27]. Other studies have suggested that this delay is not attributable to the gymnastics training per se, but rather to genetic factors or to caloric intake which is inadequate to meet the energy demands of both growth and physical training [28, 29]. Body mass index was found to be decreased in a study of gymnasts aged 7-10 years, but it was suggested that the difference was the result of selection of lean athletes [30]. This is also supported by a recent study by Damsgaard et al. [31] using longitudinal data which indicated that the individual differences in body size among sports participants was already apparent at an early age (2-4 years), suggesting a genetic influence. In a very recent study on the adolescent growth spurt and skeletal age of female gymnasts from $8.7 \pm 1.5$ to $15.5 \pm 1.5$ years, it was found that gymnasts have adolescent spurts in height, estimated leg length and sitting height that occur approximately 1 year later and are slightly less intense than in non-athletic girls [9]. The age at menarche and skeletal age were consistent with the later somatic maturation. Moreover, the adolescent growth spurts of these Belgian gymnasts were similar to those of other samples of short, normal, latematuring girls, and late-maturing girls with short parents
[9]. In general, the literature has shown that although on average young female athletes from most sports (i.e., swimmers, rowers, basketball, volleyball and tennis players) have body sizes that equal or exceed the reference medians for the normal population, gymnasts, figure skaters and ballet dancers are shorter and consistently have lighter body mass, but gymnasts also have parents who are shorter than average [1].

In aesthetic activities, such as rhythmic gymnastics, intense training usually starts long before menarche and success is strongly influenced by visual appeal and body aesthetics. As young as 9 years old, rhythmic gymnasts are often required to meet unrealistic weight goals in order to attain or maintain a favorable physique. Delayed menarche, menstrual irregularities and low body fat were found to be common in elite rhythmic gymnasts, while those who were premenarcheal had a higher training frequency and duration, as well as a lower body mass index and relative body fat when compared to menarcheal ones [11]. Further, breast development was delayed in ballet dancers who showed little or no development (Tanner stage 1 or 2 ) at 13 years of age as compared to normal children who have usually reached stage 4 at menarche [32]. Delayed menarche and breast development were observed in elite, adolescent, Canadian gymnasts when compared to age-matched controls [33]. The mixed group of adolescent artistic and rhythmic gymnasts in this study had significantly lower body weights and relative body fat values compared to the normal control participants. Accordingly, breast development was delayed in the gymnasts compared to the controls (stages $2.7 \pm 0.2$ vs. $3.8 \pm 0.1$ ), but the difference between the groups in pubic hair development did not reach significance (stages $3.1 \pm 0.2$ vs. 4.0 \pm 0.2 ).

It has also been hypothesized that when puberty is temporarily interrupted by physical training, skeletal age maturation often stalls as growth slows and gonadal steroids fall to low levels $[7,8]$. Unfortunately, only a very limited number of studies has provided some information on the excretion rate of gonadal and/or adrenal steroids in active, peripubertal girls. Malina et al. [34] have shown that the activity of hypophyso-adrenal and hypophyso-gonadal axes might be dependent upon the nature of the activity. To this end, Peltenburg et al. [35] reported that prepubertal gymnasts had lower levels of estrone, testosterone, and androstenedione than age-matched swimmers, while the circulating levels of $17 \beta$-estradiol, dehydroepiandrosterone sulfate (DHEA-S), LH, and FSH were similar between the athletic groups. In contrast, the levels of all these hormones were not different between early puber- 
tal, gymnasts and swimmers [35]. In a sample of 56 premenarcheal gymnasts (training 15-22 h/week) compared with 53 age-matched controls, no differences were found in urinary testosterone, cortisol, and DHEA-S levels, while urinary androstenedione was significantly lower in the gymnasts than in the controls [36]. As expected, in the study by Klentrou et al. [33] the plasma $17 \beta$-estradiol and progesterone levels for the premenarcheal gymnasts, whose menarche was delayed, were similar to those measured for the controls during the follicular phase, which in turn were significantly lower ( $\mathrm{p} \leq 0.05)$ than those measured for the controls during the luteal phase.

\section{Athletic Training during Adolescence}

As greater numbers of females are becoming involved in intense athletic training at a young age, health issues centering on the female athlete triad have become a concern. In some activities, especially the aesthetic and the high power to body mass sports, an increase in body weight can negatively influence performance [37]. As a result, the life of an adolescent athlete in these activities often involves a combination of intense physical training combined with pressure to meet unrealistic weight goals as a means of improving performance and/or visual appeal. Consequently, the attempt to control weight and/or achieve a desirable physique often leads to disordered eating patterns that have been associated with delays in growth and sexual maturation in adolescent athletes [38]. Disordered eating, menstrual dysfunction, and osteoporosis represent the three interrelated components of the female athlete triad, a potentially serious syndrome often seen in physically active girls and women which can result in decreased performance, both short- and long-term morbidity, and even mortality [39].

More specifically, disordered eating refers to eating behaviors used to lose or control one's body weight or to achieve a lean or aesthetic appearance [39]. It has been reported that the prevalence of pathological eating disorders, such as anorexia nervosa, bulimia nervosa and anorexia athletica, is significantly higher in athletes than in non-active controls, higher in female athletes than in male athletes, and more common among those competing in leanness-dependent and weight-dependent sports than in other sports [40]. In contrast, in a study involving $173 \mathrm{fe}-$ male Finnish athletes of various sports Fogelholm and Hiilloskorpi [41] confirmed that, although the risk of eating disorders may be dependent on the type of sport, the claim that some groups of female athletes are at greater risk than controls has not been examined adequately. Each of these behaviors can lead to disturbances in normal menstrual function. A high incidence of secondary amenorrhea has been reported for athletes in certain sports; these abnormal menstrual patterns have been shown to have a negative effect on bone mineralization, and thus may have serious short- and long-term consequences, including an increased incidence of stress fractures and osteoporosis $[39,42,43]$. Undernutrition has been associated with delays in growth and sexual maturation and even infertility $[38,42,44]$.

In a comprehensive epidemiological study, Torstveit and Sundgot-Borgen [45] investigated the percentage of female elite athletes and controls at risk of developing the female athlete triad. A detailed questionnaire, which included questions regarding training and/or physical activity patterns, menstrual history, oral contraceptive use, weight history, eating patterns, dietary history, and the Body Dissatisfaction and Drive for Thinness subscales of the Eating Disorder Inventory, was completed by a substantial cohort of athletes and non-athletic controls. The battery of questionnaires was administered to the total population of female elite athletes in Norway, representing both the junior and senior national teams (age range $13-39$ years; $n=669$ ), and a group of age-matched controls $(\mathrm{n}=607)$. The study revealed interesting results: (a) a higher percentage of controls (69.2\%) than athletes $(60.4 \%)$ was classified as being at risk of developing the female athlete triad ( $\mathrm{p} \leq 0.01$ ); (b) similarly, a higher percentage of controls reported use of pathogenic weightcontrol methods, and (c) the controls had higher Body Dissatisfaction scores $(p \leq 0.001)$. However, (a) more athletes reported menstrual dysfunction and stress fractures as compared to controls ( $\mathrm{p} \leq 0.05$ ), and (b) the percentage of athletes competing in leanness sports (70.1\%) and the percentage of controls (69.2\%) classified as being at risk of developing the female triad were higher when compared to athletes competing in sports that did not have an emphasis on leanness (55.3\%; $\mathrm{p} \leq 0.001$ ) [45]. Furthermore, a higher percentage of athletes competing in aesthetic sports (66.4\%) than ball game sports (52.6\%) was classified as being at risk of the triad ( $\mathrm{p} \leq 0.001)$. It was concluded that athletes competing in sports that emphasized leanness, as well as non-athlete controls, were classified as being at risk of developing the triad when compared to athletes competing in non-leanness sports, such as ball games [45]. The results of the Norwegian study support the assumption that a significant proportion of female athletes suffer from one or more components of the triad $[45,46]$. It is also important to empha- 
size that the authors reported a significant risk of developing the triad in normal active females. Therefore, programs/educational tools need to be developed to help prevent the triad, and furthermore, these programs need to be geared towards all physically active girls and young women [46].

\section{Menstrual Irregularities in Puberty}

Menstrual irregularities include primary amenorrhea (defined as the absence of menstruation by age 16), secondary amenorrhea (defined as the absence of menses for 3 or more months in women who have reached menarche) or oligomenorrhea (defined as a menstrual cycle duration of $>40$ days) have been observed among adolescent athletes. The prevalence of 'athletic amenorrhea' varies among adolescent athletes from 12 to $66 \%[47,48]$. To estimate the influence of intensive training on menstrual cycles in female athletes, Dusek [12] examined the time of menarche and the prevalence of primary and secondary amenorrhea and dysmenorrhea in 72 young, active, female athletes (15-21 years of age) and 96 age-matched controls not engaged in any organized or regular sports activity. The athletic sample included volleyball players, basketball players, ballet dancers, and runners. The results showed that the prevalence of secondary amenorrhea was three times higher in athletes than in controls ( $p \leq 0.05)$. The prevalence of primary amenorrhea was substantially higher in athletes than in controls ( $\mathrm{p} \leq$ 0.05 ), yet the prevalence of dysmenorrhea was twofold lower in athletes than in controls ( $\mathrm{p} \leq 0.001)$. The highest prevalence of secondary amenorrhea was recorded in runners, particularly long-distance runners, whereas there was only 1 case of secondary amenorrhea among basketball players [12]. Long-distance runners were also lighter and leaner than controls and athletes of other sports $(\mathrm{p} \leq 0.05)$. In a previous study by Toriola [49], menstrual function was assessed in different categories of 155 Nigerian athletes (13-19 years of age) and 135 controls (12-18 years of age). Menstruation was more regular in controls (44\%) than athletes (21\%), whereas secondary amenorrhea or oligomenorrhea was more prevalent in athletes $(25 \%)$ than in controls $(10 \%)$. Regardless of the sports activity, the oligomenorrheic subjects had a substantially lower body weight relative to stature, and were leaner than the subjects comprising the other menstrual categories [49]. In the oligomenorrheic group, a greater proportion of athletes (59\%) and controls (57\%) had lean body mass values below the 41st percentile [49]. Men- strual disturbances have also been reported to be relatively more common in athletes who began training before the menarche $[49,50]$.

Recently, Torstveit and Sundgot-Borgen [10] examined the prevalence of menstrual dysfunction in the total population of elite Norwegian female athletes $(n=669)$ representing the country at the junior or senior level (aged 13-39 years) and compared this to a representative agematched national control sample $(\mathrm{n}=607)$. A detailed questionnaire including questions on training and/or physical activity patterns, menstrual, dietary and weight history, oral contraceptive use, and eating disorder inventory was administered to all the subjects. The results indicated that a higher percentage of athletes $(7.3 \%)$ than controls $(2.0 \%)$ reported a history of primary amenorrhea $(\mathrm{p} \leq 0.001)$. In addition, a higher percentage of athletes competing in leanness sports reported current menstrual dysfunction $(24.8 \%)$ than athletes competing in nonleanness sports (13.1\%; $p \leq 0.01)$ and controls ( $p \leq 0.05$ ) [10]. These data include virtually all eligible elite athletes, and thus substantially extend previous studies. The authors suggested that the prevalence of menstrual dysfunction between elite athletes and controls is not as large as previously assumed, and that the prevalence of menstrual dysfunction is lower in both athletes and controls when compared to observations made 1 decade previously [10]. Nevertheless, a higher percentage of athletes competing in sports that emphasize thinness and/or a specific weight reported present menstrual dysfunction than athletes competing in sports focusing less on such factors [10].

Cross-sectional studies of amenorrheic athletes have shown abnormal reproductive hormone patterns, suggesting that the normal secretion of GnRH by the hypothalamus is disrupted and, as a result, there is a failure to initiate normal hypothalamic-pituitary-ovarian function, leading to a decrease in the release of gonadotropins. Gonadotropic and ovarian hormonal levels in amenorrheic athletes show no monthly follicular and luteal phase variation, i.e., evidence of ovarian suppression. Luteal-phase estradiol and progesterone concentrations for the single menarcheal gymnast in the study by Klentrou et al. [33] were lower than the concentrations measured in controls. On the other hand, the $17 \beta$-estradiol levels reported in this study for the control subjects did not reach adult levels for either the follicular or luteal phase, but they were similar to those previously reported for adolescents, and the plasma progesterone levels of the controls were in the same range as those reported for adults. Previous studies have also reported lower levels of luteal phase estradiol and progesterone in teenage swimmers compared to age- 
matched controls and adults, leading to the suggestion that the corpora lutea in the swimmers were not functioning properly [51]. Ovulatory dysfunction has also been observed in regularly menstruating competitive athletes, with results showing that progesterone levels are lower during the luteal phase [38]. The suggested causes of these alterations include: (a) severe protein-caloric restrictioninduced hypercortisolism (increased secretion of corticotropin-releasing hormone), which leads to an alternation in the normal episodic secretion pattern of LH [47, 52]; (b) a hypo-estrogenism due to suppression of the $\mathrm{GnRH}$ pulse generator, and (c) lack of a positive estrogen feedback mechanism. The suggested mechanism causing menstrual irregularities in swimmers has been reported to be hyperandrogenism [14].

During puberty, maturation of the hypothalamic-pituitary axis leads to an increase in both the frequency and amplitude of the pulsatile secretion of $\mathrm{GnRH}$, resulting in an increase in the pulsatile secretions of LH, FSH and sex steroids. The timing of the pulses is essential to the establishment of normal ovulatory cyclicity. The LH spike occurs at night during early puberty, and throughout the day and night with a lower amplitude being seen at night during late puberty and adulthood [53]. In the early menarcheal years, the hypothalamic-pituitary-ovarian feedback is unstable due to an increase in basal LH and an 'immature timing of the LH pulses. This results in irregular menstrual cycles, ovarian hyperandrogenism, multi-follicularity and anovulation [54]. Hence, infrequent, irregular and anovulatory cycles, abnormal uterine bleeding, and dysmenorrhea are common during the first postmenarcheal years [2, 3]. During normal pubertal development, a cycle may be considered normal if its length is 21-40 days, blood loss is $20-80 \mathrm{ml}$, and the duration of menses is $2-8$ days $[2,3]$. The final step of maturation is the development of positive estrogen feedback on the pituitary and hypothalamus, which stimulates the mid-cycle LH surge required for ovulation. The lack of positive estrogen feedback in the first year after menarche results in anovulatory cycles, and may also reflect a normal transient step in ovarian hyperandrogenism [3]. Moreover, adolescent ovulatory cycles are characterized by a long follicular phase, late ovulation, and a short insufficient luteal phase. The selection of a dominant follicle is irregular and the developed follicle is smaller in diameter than in adulthood [55]. All these irregularities usually resolve with the onset of regular ovulation $[2,3]$. Thus, athletic amenorrhea may simply be a sign of late puberty or a caloric restriction-induced problem affecting the hypothalamic-pituitary-ovarian axis.

Puberty in Female Athletes

\section{Role of Caloric Restriction}

In the context of this material, disordered eating can be used synonymously with undernutrition. As mentioned above, a major health concern for the young, female, highperformance athlete is that her caloric intake is insufficient for the mount of energy being expended during daily training. The combination of intensive exercise and undernutrition has a profound effect on the release of gonadotropins, activation of the gonadal axis, the timing of puberty, and the onset of menstrual disorders in adolescent athletes [32, 44]. In addition, less severe forms of food restriction, relative to energy output, have been associated with inadequate luteal phases and anovulation, as well as abnormal LH and FSH surges during the menstrual cycle [38].

The normal process of the menstrual cycle is regulated by the complex interactions of the ovarian hormones. The levels of several of these hormones are altered by intense exercise. These alterations may also have implications for substrate utilization during exercise. Zderic et al. [56] point out that, in a properly nourished female athlete, estradiol mediates changes in carbohydrate and fat metabolism. Thus, carbohydrate and fat oxidation may be regulated differently across the menstrual cycle because of the large changes in circulating ovarian hormones. When estradiol is elevated in the luteal phase, the production and concentration of lactic acid is decreased as there is an increased reliance on fat oxidation. Females exhibit a greater reliance on fat when lactate is lowered regardless of exercise intensity, suggesting that the utilization of lipids may be a direct effect of the elevated estradiol [5]. While there is a clear, direct association between fuel utilization and reproductive function, the question remains whether there is also an interaction between fuel availability and reproduction.

As previously mentioned, it has been declared that females must attain a minimum level of body fat in order to pass through puberty and maintain a normal cycle [24]. This 'critical fat hypothesis' has been restated in many venues, and has been accepted by clinicians. However, according to new reports, in actual fact there is no direct cause-effect association between fatness and reproductive function and, although they tend to be correlated with one another, body fat and amenorrhea have not been causally related [57-60]. Instead, a new theory - the metabolic fuels hypothesis - has been developed which states that energy availability, and not body fat, regulates reproductive function in females. In brief, this hypothesis suggests that reproductive function, like food intake, is responsive to

Ann Nestlé [Engl] 2006;64:85-94 
Fig. 1. Schematic presentation of the nutritional controls of reproductive physiology in females. Modified from Wade and Jones [60].

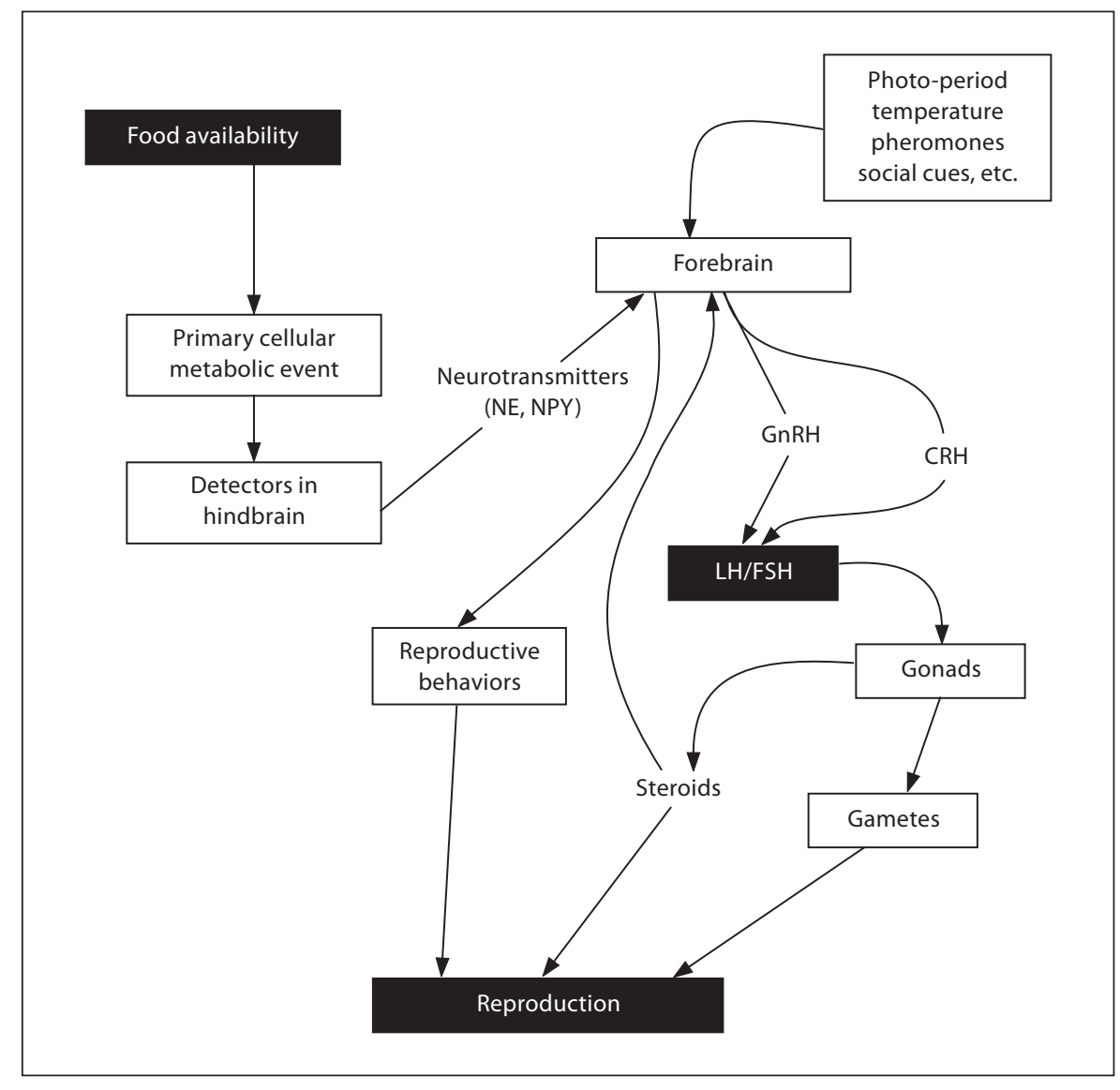

short-term changes in metabolic fuel oxidation. $\mathrm{LH}$, and by inference $\mathrm{GnRH}$, secretion responds almost instantly to abrupt changes in metabolic fuel oxidation [61]. Fuel detectors in the hindbrain appear to participate in the control of LH release. Once the visceral hindbrain detects the information concerning fuel availability, it sends direct and indirect projections to those regions of the forebrain known to play important roles in the regulation of both energy balance and reproductive function (fig. 1). Projections containing both catecholamines and neuropeptide $\mathrm{Y}$ have been identified as participating in this pathway [60]. Further, catecholamine and neuropeptide Y projections on the forebrain can also stimulate corticotropin-releasing hormone secretion leading to hypercortisolism, which has previously been suggested to play a prominent role in the suppression of $\mathrm{LH}$ pulses during undernutrition in young female athletes $[47,52]$. However, significantly more research will be needed to further investigate this interaction between short-term changes in fuel availability and athletic amenorrhea, especially that involving puberty.

\section{Conclusions}

In sport, the initiation of intense physical training at a very young age puts significant stress on the body during a critical developmental period, especially in young females. The combination of intensive exercise and undernutrition may have an effect on the onset of puberty and sexual maturation in female athletes, especially those involved in sports where weight control (i.e., those in which making a weight category or maximizing one's power to weight ratio) or aesthetic appearance is an integrated performance strategy or a critical component of successful performance.

While some studies have suggested that delayed menarche may be due to genetic factors, there is considerable evidence that environmental factors also play a significant role. Given the many factors that have been shown to influence menarche, the role played by physical training alone as a causative factor in the later onset of puberty in active females is still unclear. A higher prevalence of menstrual dysfunction has been reported for adolescent ath- 
letes in leanness-dependent and weight-dependent sports as compared to those in other sports. The available research supports the role of nutrition-related factors and energy balance, as well as the timing of the initiation of intense training, in the etiology of exercise-associated menstrual irregularities in pubertal athletes. Future research should be longitudinal in nature in order to investigate the long-term effects of sport training and to examine the role that fuel availability and utilization have on the growth and maturation of young females.

\section{References}

$\checkmark 1$ Baxter-Jones ADG, Maffulli N: Intensive training in elite young female athletes. Br J Sports Med 2002;36:13-15.

2 Caufriez A: Menstrual disorders in adolescence: pathophysiology and treatment. Horm Res 1991;36:156-159.

3 Hamm T: Physiology of normal female bleeding. NAACOGS Clin Issu Perinat Womens Health Nurs 1991;2:289-293.

4 Lindholm C, Hagenfeldt K, Rangertz B: Pubertal development in elite juvenile gymnasts. Effects of physical training. Acta Obstet Gynecol Scand 1994;73:269-273.

5 Bunt JC: Metabolic actions of estradiol: significance for acute and chronic exercise responses. Med Sci Sports Exerc 1990;22:286290.

6 Mansfield M, Emans J: Growth in female gymnasts: should training decrease during puberty? J. Pediatr 1993;122:237-240.

7 Theintz GE: Endocrine adaptation to intensive physical training during growth. Clin Endocrinol 1994;41:267-272.

$>8$ Theintz GE, Ladame F, Howald $\mathrm{H}$, et al: L'enfant, la croissance et le sport de haut niveau. Schweiz Z Med Traumatol 1994;3: 7-15.

-9 Thomis M, Claessens AL, Lefevre J, Philippaerts R, Beunen GP, Malina RM: Adolescent growth spurts in female gymnasts. J Pediatr 2005;146:239-244

10 Torstveit MK, Sundgot-Borgen J: Participation in leanness sports but not training volume is associated with menstrual dysfunction: a national survey of 1276 elite athletes and controls. Br J Sports Med 2005;39:141147.

11 Klentrou P, Plyley M: Onset of puberty, menstrual frequency, and body fat in elite rhythmic gymnasts compared with normal controls. Br J Sports Med 2003;37:490-494.

12 Dusek T: Influence of high intensity training on menstrual cycle disorders in athletes. Croat Med J 2001;42:79-82.

13 Pigeon P, Oliver I, Charlet JP, Rochiccioli P: Intensive dance practice: repercussions on growth and puberty. Am J Sports Med 1997; $25: 243-247$

14 Constantini NW, Warren MP: Menstrual dysfunction in swimmers: a distinct entity. J Clin Endocrinol Metab 1995;80:2740-2744.

15 Malina RM, Ryan RC, Bonci CM: Age at menarche in athletes and their mothers and sisters. Ann Hum Biol 1994;21:417-422.
6 Hata E, Aoki K: Age at menarche and selected menstrual characteristics in young Japanese athletes. Res Q Exerc Sport 1990;61: 178-183.

17 Calabrese LH: Nutritional and medical aspects of gymnastics. Clin Sports Med 1985; $4: 23-30$.

18 Calabrese LH, Kirkendall DT, Floyd M Menstrual abnormalities, nutritional patterns, and body composition in female classical ballet dancers. Phys Sportsmed 1983;11: 86-98.

19 Malina R: Menarche in athletes: a synthesis and hypothesis. Ann Hum Biol 1973;10:124.

20 Baxter-Jones ADG, Helms PJ: Effects of training at a young age: a review of the training of young athletes (TOYA) study. Pediatr Exerc Sci 1996;8:310-327.

21 Kaprio J, Rimpela A, Winter T, Viken RJ, Rimpela M, Rose RJ: Common genetic influences on BMI and age at menarche. Hum Biol 1995;67:739-753.

22 Malina RM, Waynarowska B, Bielicki T, et al: Prospective and retrospective longitudinal studies of the growth, maturation and fitness of Polish youth active in sports. Int J Sports Med 1997;18(suppl):S179-S185.

23 Frisch R, Gotz-Welbergen AV, McArthur JW: Delayed menarche and amenorrhea of college athletes in relation to age of onset of training. JAMA 1981;246:1559-1563.

24 Frisch RE, McArthur JW: Menstrual cycles: Fatness as a determinant of minimum weight for height necessary for their maintenance or onset. Science 1974;185:949-951.

25 Bass, S, Pearce, G, Bradney, M, et al: Exercise before puberty may confer residual benefits in bone density in adulthood: studies in active prepubertal and retired female gymnasts. J Bone Miner Res 1998;13:500-507.

26 Theintz GE, Howald H, Weiss U, et al: Evidence for a reduction of growth potential in adolescent female gymnasts. J Pediatr 1993; 122:306-313

27 Bass S, Bradney M, Pearce G, et al: Short stature and delayed puberty in gymnasts: influence of selection bias on leg length and the duration of training on trunk length. J Pediatr 200;136:149-155.

28 Ledoux M, Brisson G, Peronnet F: Nutritional habits of young female gymnasts. Med Sci Sports Exerc 1983; 14:145.
29 Ersoy G: Dietary status and anthropometric assessment of child gymnasts. J Sports Med Phys Fitness 1991;31:577-580.

-30 Benardot D, Czerwinski C: Selected body composition and growth measures of junior elite gymnasts. J Am Diet Assoc 1991;91:29_ 33.

31 Damsgaard R, Bencke J, Matthiesen G, et al: Is pubertal growth adversely affected by sport? Med Sci Sports Exerc 2000;32:16981703.

32 Warren MP: The effects of exercise on pubertal progression and reproductive function in girls. J Clin Endocrinol Metab 1980;51:11501157.

33 Klentrou P, Flouris AD, Plyley M: Pubertal maturation, hormonal levels and body composition in Canadian male and female gymnasts; in Marfell-Jones M, Stewart A, Gordon R, Olds T (eds): Kinanthropometry IX. Proc 9th Int Conf International Society for the Advancement of Kinanthropometry (ISAK). London, Routledge, 2006, in press.

34 Malina RM, Waneen W, Spirduso CT, Baylor A: Age at menarche and selected menstrual characteristics in athletes at different competitive levels and in different sports. Med Sci Sports 1978;10:218-222.

35 Peltenburg AL, Erich WBM, Thijssen JJH, et al: Sex hormone profiles of premenarcheal athletes. Eur J Appl Physiol 1984;52:385392.

-36 Jaffré C, Lac G, Benhamou CL, Courteix D: Effects of chronic intensive training on androgenic and cortisol profiles in premenarcheal female gymnasts. Eur J Appl Physiol 2002;87:85-89.

37 Wilmore $\mathrm{JH}$ : Body weight standards and athletic performance; in Brownell KD, Rodin J, Wilmore JH (eds): Eating, Body Weight and Performance in Athletes: Disorders of Modern Society. Philadelphia, Lea \& Febiger, 1992, pp 315-329.

38 Loucks AB, Vaitukaitis J, Cameron JL, et al: The reproductive system and exercise in women. Med Sci Sports Exerc 1992;24(suppl):S288-S293.

39 Yeager KK, Agostini R, Nattiv A, et al: The female athlete triad. Med Sci Sports Exerc 1993;25:775-777.

40 Sundgot-Borgen J, Torstveit MK: Prevalence of eating disorders in elite athletes is higher than in the general population. Clin J Sport Med 2004;14:25-32. 
-41 Fogelholm M, Hiilloskorpi H: Weight and diet concerns in Finnish female and male athletes. Med Sci Sports Exerc 1999;31:229235.

-42 Drinkwater BL, Nilson K, Chesnut CH, et al: Bone mineral content of amenorrheic and eumenorrheic athletes. N Engl J Med 1984; 311:277-281.

43 DiFiori JP: Menstrual dysfunction in athletes. How to identify and treat patients at risk for skeletal injury. Postgrad Med 1995; 97:143-156.

44 Loucks AB, Mortola JF, Girton L, et al: Alterations in the hypothalamic-pituitaryovarian and the hypothalamic-pituitary-adrenal axes in athletic women. J Clin Endocrinol Metab 1989;68:402-411.

-45 Torstveit MK, Sundgot-Borgen J: The female athlete triad: are elite athletes at increased risk? Med Sci Sports Exerc 2005;37:184193.

-46 Torstveit MK, Sundgot-Borgen J: The female athlete triad exists in both elite athletes and controls. Med Sci Sports Exerc 2005;37: 1449-1459.

-47 Constantini NW, Warren MP: Special problems of the female athlete. Baillieres Clin Rheumatol 1994;8:199-219.
48 Patterson DF: Menstrual dysfunction in athletes: assessment and treatment. Pediatr Nurs 1995;21:227-229, 310.

49 Toriola AL: Survey of menstrual function in young Nigerian athletes. Int J Sports Med 1988;9:29-34.

50 Toriola AL, Mathur DN: Menstrual dysfunction in Nigerian athletes. Br J Obstet Gynaecol 1986;93:979-985.

51 Bonen A, Belcastro AN, Ling WY, et al: Profiles of selected hormones during menstrual cycles of teenage athletes. J Appl Physiol 1981;50:545-551.

52 Fichter MM, Pirke KM: Effect of experimental and pathological weight loss upon the hypothalamo-pituitary-adrenal axis. Psychoneuroendocrinology 1986;11:295-305.

53 Wenninck JMB, Delemarre-Van De Waal HA, Shoemaker R, Shoemaker H, Shoemaker J: Luteinizing hormone and follicle stimulating hormone secretion patterns in girls throughout puberty measured using highly sensitive immunoradiometric assays. Clin Endocrinol 1990;33:333-344.

54 Venturoli S, Porcu E, Fabbri R, et al: Ovarian multifollicularity, high LH and androgen plasma levels, and anovulation are frequent and strongly linked in adolescent irregular cycles. Acta Endocrinol 1986;111:368-372.
55 Apter D, Räisänen I, Ylöstalo PRV: Follicular growth in relation to serum hormonal patterns in adolescent compared with adult menstrual cycle. Fertil Steril 1987;47:82-88.

56 Zderic TW, Coggan AR, Ruby BC: Glucose kinetics and substrate oxidation during exercise in the follicular and luteal phases. J Appl Physiol 2001;90:447-453.

57 Bronson FH, Manning JM: The energetic regulation of ovulation: a realistic role for body fat. Biol Reprod 1991;44:945-950.

58 Loucks AB, Verdun M, Heath EM: Low energy availability, not stress of exercise, alters LH pulsatility in exercising women. J Clin Endocrinol Metab 1998;84:37-46.

59 Loucks AB: Energy availability, not body fatness, regulates reproductive function in women. Exerc Sports Sci Rev 2003;31:144148.

60 Wade GE, Jones JE: Lessons from experimental disruption of estrous cycles and behaviors. Med Sci Sports Exerc 2003;35:15731580.

61 Schneider JE, Wade GN: Inhibition of reproduction in service of energy balance; in Wallen K, Schneider JE (eds): Reproduction in Context. Cambridge, MIT Press, 1999, pp 35-82. 